\title{
Some Considerations in the Use of Monetary Aggregates for the Implementation of Monetary Policy
}

\author{
LEONALL C. ANDERSEN and DENIS S. KARNOSKY
}

O

VER the past several years, the Federal Reserve System has paid increased attention to monetary aggregates as a means to achieve the ultimate national employment and price goals. Evaluation and further development of this process has been hindered, however, by a continuing controversy about which monetary aggregate is appropriate. Specifically, the question concerning the efficacy of monetary actions often becomes lost in discussions about whether M1 or M2 or some other monetary aggregate is giving the best information about the monetary influences being transmitted to the economy.

The Federal Open-Market Committee (FOMC) currently specifies desired ranges for three monetary aggregates in terms of average growth rates over four quarters from a recent base period. ${ }^{1}$ Adoption of this strategy represents a compromise in the controversy regarding the appropriate monetary aggregate for the implementation of monctary policy.

Two questions are at issue in this controversy. (1) Which monetary aggregate projects future patterns of economic activity with the smallest error? (2) Which monetary aggregate can the Federal Reserve control with the smallest error? While considerable attention has been given to answering the first question, much less effort has been directed toward resolving the second, but equally important, issue, ${ }^{2}$

\footnotetext{
The aggregates are currency plus demand deposits held by the norbank public (M1), M1 plus time deposits at commercial banks other than large marketable certificates of deposit (M2), and M2 plus saving accounts at savings and loan associations and mutual savings banks (M3).

uOne study, for example, found that in predictions over fout quarter periods from 1962 to 1974, using numerous measures of monetary aggregates, the smallest mean and variance of projection errors was associated with the monetary base. See Lemall C. Andersen, "Selection of a Monetary Aggregate for Economic Stabilization," this Retiew (October 1975), pp. 9-15. The study presented here is an elaboration on the evaluation of sich tests.
}

The purpose of this article is to address the issue of the appropriate monetary aggregate for the implementation of monetary policy. In this light, the overall question at hand involves how the Federal Reserve can transmit its direct actions through some monetary aggregate (such as M1 or M2) and ultimately to the pattern of economic activity with a minimum of slippage or error.

\section{SOTRCHS OF whOM}

The appropriate monetary aggregate for achieving a desired pattern of economic activity would be the one with the smallest probability of error - projection error plus control error. The controversy can only be settled by taking into consideration both types of error. While a particular monetary aggregate might give very good projections of the likely pattern of economic activity, that information is not very useful to the monetary authorities for achieving a desired pattern if they have virtually no control over that aggregate.

The ultimate concem of monetary policymakers is the general pattern of economic activity, such as aggregate output, employment, and prices. Evaluation of the appropriate monetary aggregate, for policy purposes, therefore requires a choice among the various measures of economic activity. Nominal GNP is the candidate adopted here, since it incorporates, in a general way, the major variables addressed in policy deliberations. While nominal GNP is not the explicit goal of monetary policy, its use here avoids such debatable issues as the weight that inflation is given in policy discussions relative to output, employment, and other considerations." Also, since the FOMC has

\footnotetext{
3The use of nominal GNP also casts the issue in terms of the recent discussions about the velocities of various nonetary aggregates in recent years and their implications for the
} 
usually placed its main emphasis on $\mathrm{M} 1$ and $\mathrm{M} 2$, attention is focused on those aggregates, along with the monetary base.

\section{Control Wrom}

Achievement of the specified ranges of growth rates of the monetary aggregates is implemented mainly through open-market purchases and sales of Government securities by the Federal Reserve System. These day-to-day activities are the means by which the Federal Reserve attempts to achieve its Ionger term monetary growth targets. These activities can be summarized by changes in the monetary base.

The monetary base is derived from the consolidated monetary accounts of the Treasury and the Federal Reserve System, ${ }^{4}$ It is an asset held by the public in the form of currency and by commercial banks in the form of reserves. The major and dominant source of change in the monetary base is the open-market transactions of the Federal Reserve. Since these transactions can generally be used to offset changes in other sources, changes in the monetary base are, for all practical purposes, under the direct control of the Federal Reserve, ${ }^{5}$

Thus, while the Federal Reserve has not decided explicitly to control the monetary base, all of their actions can be subsumed into changes in the base. Even though the Federal funds rate currently is used as the day-to-day operating target in the implementation of monetary policy, open-market operations to achieve desired changes in that rate result in changes in the monetary base. The monetary base, therefore, serves well as a summary measure of the monetary actions of the Federal Reserve.

Money (M), however defined, is related at a point in time to the monetary base (B) by a money multiplier $(m)$ in the following identity:

$$
\text { (1) } \mathrm{M}=\mathrm{mB} \text {. }
$$

There are, of course, different multipliers for $\mathrm{MI}$ and M2. This framework offers a concise method of ac-

conduct (and evaluation) of monetary actions. See, for example, "The Fiftl Report on the Conduct of Monetary Policy," U.S., Senate, 95th Congress, Committee on Banking, Housing, and Urban Affairs, Augtist 5, 1977.

4 For a detaled discussion of the monetary base, see Anatol B. Balbach and Albert E. Burger, "Derivation of the Monetary Base," this Review (November 1976), pp. 2-8.

5See Jack L. Rutner, "The Federal Reserve's Impact on Seweral Reserve Aggregates," Federal Reserse Bank of Kansas City Monthy Review (May 1977), pp. 14-22. counting for public and commercial bank preference, which in turn can affect the amount of money which exists in the economy. The multipliers reflect the public's desired holdings of currency and time deposits relative to private demand deposits, commercial banks' desired holdings of excess reserves relative to private demand deposits, Federal government's holdings of demand deposits relative to private demand deposits, and the distribution of deposits among classes of banks."

Since the money identity (equation (1) above) is multiplicative, the percent change in money $(M)$ can be separated into two components - the percent change in the multiplier $(\mathrm{m})$ and the percent change in the monetary base (B). Using changes in natural logarithms to approximate percentage changes gives:

$$
\text { (2) } \Delta \ln M=\Delta \ln m+\Delta \ln B
$$

Identity (2) separates a change in money $(\Delta \ln M)$ into the effects caused by the change in the component $(\Delta \ln B$ ) which is under the direct control of the Federal Reserve from those effects caused by the change in the component ( $\Delta \mathrm{hm}$ ) which is not under the Federal Reserve's direct control. ${ }^{\top}$ In order to achieve a desired change in money, it would be necessary for the Federal Reserve to forecast (at least implicitly) changes in the multiplier. These multipliers are not constant, nor do they change at a constant rate. Instead, they move in response to changes in the public's monetary preferences and management of Govermment's demand deposits.

These events, if not properly anticipated by the Federal Reserve, would be the source of control error in the implementation of monetary policy. Actions of the public and the Government can either dampen or exaggerate the effect of any Federal Reserve action on a particular monetary aggregate. The predictability of these changes in the multiplier, even if considered only implicitly, is an important consideration in determining appropriate policy actions.

Changes in the multiplier can be divided into two components - the predicted element ( $\Delta \mathrm{h} \hat{\mathrm{m}})$, which is not necessarily constant and may perhaps be

Wor a detailed analysis, see Jerry L. Jordan, "Elements of Money Stock Detemination," this Review (October 1969), pp. 10-19.

Identity (2) does not imply that the multiplier is independent of changes in the base. Factors affecting the multiplier are considered later. Forecasts of the multipliers can consist of: projections of the multipliers per se, the components of the multipliers, or variables which make up the various components or ratios. These forecasts are, in effect, projections of the demand for a particular monetary aggregate. 
related to changes in the base, and the unpredicted element $(\varepsilon)$.

$$
\text { (3) } \Delta \ln m=\Delta \ln \hat{m}+\varepsilon
$$

Over any period of time, the percent change of a particular monetary aggregate is equal to the percent change in the monetary base $(\Delta \ln B)$, the predicted portion of the percent change of the multiplier $(\Delta \ln \hat{\mathrm{m}})$ and the nompredicted portion of the percent change of the multiplier $(\varepsilon)$. The term $(\varepsilon)$ represents the control error over a particular period.

$$
\text { (4) } \Delta \ln M=\Delta \ln B+\Delta \ln \hat{\mathrm{m}}+\varepsilon
$$

\section{Projecton Ertors}

Addressing the problem of projection errors is much more complicated than the control error problem. The framework of the latter problem is relatively straightforward, involving simple accounting relationships between the balance sheets of the public, commercial banks, and the monetary authorities. The underlying accounting relationships are identities and all the complexities of changes in ptiblic, commercial banks, and Government behavior can be lumped together in one term - the money multiplier.

The mechanism which links the various monetary aggregates to economic activity is more obscure, more complex, and a point of dispute among economic analysts. In general, however, the percent change in nominal GNP $(\Delta \ln Y)$ is related to the percent change in money, changes in other exogenous variables, and random disturbances. The question is, of course, what specific form does this relationship take? The presumption adopted here is that an equation which relates the percent change of nominal GNP to the percent change of money only is sufficient for the empirical comparisons made in this article.

$$
\text { (5) } \Delta \ln Y=a_{0}+a_{1} \Delta \ln M+\mu
$$

In this equation, the constant term $\left(a_{0}\right)$ embodies the average influence of changes in the omitted exogenous variables. The term $(\mu)$ embodies the systematic influence of changes in the omitted variables and the random disturbances. The projection error for a particular period is $(\mu)$.

\footnotetext{
There is considerable evidence that the response of nominal GNP to a change in money is distributed over time. For the sake of simplicity, lagged money terms are not included in equation (5), but they are considered in the empirical analysis later in this article.

In general, the exclasion of important variables from a relationship will bias estimates of the remaining coefficients and the distribution of the error term. Fstimates of the mean
}

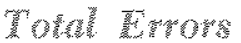

Substituting equation (4) into (5) yields the following equations for the percent change in nominal GNP, where money is defined as $\mathrm{M} 1$ in the first equation and $\mathrm{M} 2$ in the second.

$$
\begin{aligned}
& \text { (5a) } \Delta \ln Y=a_{0}+a_{1} \Delta \ln \hat{m}_{1}+a_{1} \Delta \ln B+\left(a_{1} \varepsilon_{1}+\mu_{1}\right) \\
& \text { (5b) } \Delta \ln Y=b_{0}+b_{1} \Delta \ln \hat{m}_{2}+b_{1} \Delta \ln B+\left(b_{1} \varepsilon_{2}+\mu_{2}\right)
\end{aligned}
$$

The terms $\left(a_{1} \varepsilon_{1}+\mu_{1}\right)$ and $\left(b_{1} \varepsilon_{2}+\mu_{2}\right)$ are the measured total errors in achieving the desired percent change in nominal GNP by using each concept of money - errors in achieving a desired change in money plus errors in projecting nominal GNP from the actual change in money.

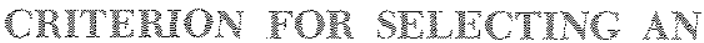

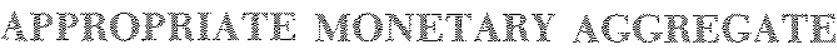

The criterion for selecting among monetary aggregates is based on the mean and variance of the total error in achieving a desired percent change in nominal GNP, using equations (5a) and (5b), for a given set of Federal Reserve actions. ${ }^{10}$ The total errors in achieving desired changes in nominal GNP for the two concepts of money are given by the following equations:

$$
\begin{aligned}
& \gamma_{1}=a_{1} \varepsilon_{1}+\mu_{1}, \text { for } M 1, \text { and } \\
& \gamma_{2}=b_{1} \varepsilon_{2}+\mu_{2}, \text { for } M 2 .
\end{aligned}
$$

and variance of the errors will be biased according to the de gree of correlation between the included and excluded variables. If the true relationship between nominal incone and money is

$$
\Delta \ln \mathrm{Y}=\mathrm{a}^{\prime}+\mathrm{a}^{\prime} \Delta \ln \mathrm{M}+\mathrm{a}_{2} \Delta \ln \mathrm{Z}+\mu^{\prime}
$$

the estimated variance of $\mu^{\prime}$ will be overstated by the estimated variance of $\mu$. The greater the correlation between $\Delta \ln M$ and $\Delta$ in $Z$, the larger this effect will be. Although some of the effect of as $\Delta$ in $Z$ will be captured in the constant of equation $(5)$, the estimated variance of $\mu$ will probably understate the variance of non-monetary intuences on nomina $\mathrm{CNP}$ (a) $\Delta$ ln $Z+\mu^{*}$ ). This underestmate also will depend on the degree of correlation between $\Delta$ In $M$ and $\Delta \ln \mathrm{Z}$. However, one study which included other exogenous variables such as govermment spending, export demand and strike dummies, gave results which suggest strongly that while equation (5) might give biased estimates of the projection error, the relative errors between various monetary aggregates are not adversely affected. See Andersen, "Selection of a Monetary Aggregate," p. 14 .

19There is no firm rule for choosing between mean and variance as a criterion. Instead, it is a decision appropriate for the policynakers, based on their preferences. While monetary policy is made over one year the horizons, shortrtm developments often have been important. Thus, an average error of near zero, but with relatively large variance might not be preferable to a somewhat larger average error, but with significantly smaller variance. In essence, the question is whether the policymakers prefer infrequent but large errors to more regular but relatively small errors. 
This basis for a criterion can be cumbersome to apply, however, requiring estimates of the errors in predicting the $\mathrm{M} 1$ and $\mathrm{M} 2$ multipliers. ${ }^{11} \mathrm{~A}$ criterion can be developed, however, on a less straightforward, but still rigorous, basis. To facilitate development of this criterion, it is convenient to consider a hypothetical and unspecified monetary aggregate $\left(\mathrm{M}^{\circ}\right)$. This aggregate may be $\mathrm{M} 1$ or $\mathrm{M} 2$, or it may be one of the numerous other monetary aggregates that have been mentioned in the controversy. For the moment, its exact composition is not important. This variable is defined as that monetary aggregate which gives the smallest total error - control plus prediction. ${ }^{12}$ Using this variable, equation (5) is written as

(5o) $\Delta \ln Y=c_{0}+c_{1} \Delta \ln \hat{m}^{*}+c_{1} \Delta \ln B+\left(c_{1} \varepsilon^{*}+H^{*}\right)$

Also,

$$
\gamma^{*}=c_{1} \varepsilon^{*}+\mu^{*} .
$$

Since $\gamma^{\circ}$ is defined as having the smallest total error, the errors for $\mathrm{M} 1$ and M2 must be at least as large as the error using $M^{*}$. That is

$$
\gamma_{1} \geq \gamma^{*} \leq \gamma_{2}
$$

The specification of equation (5) in terms of $\mathrm{M}^{\circ}$ allows comparison of the total errors of using M1 and M2 to the errors that would be made using the monetary base directly as the monetary target in the implementation of monetary policy. Thus, a joint problem can be addressed. First, if the Federal Reserve is interested in pursuing a monetary aggregate (as opposed to interest rate) policy, is an intermediate target, like M1 or M2, required? Second, if an intermediate target seems to work better than using the monetary base directly, which aggregate serves better?

Two further assumptions are made in developing the criterion. The first assumption is that, without considering the available evidence, the errors in forecasting the multipliers for $\mathrm{M} 1$ and $\mathrm{M} 2$ are zero $\left(\varepsilon_{1}=\varepsilon_{2}=0\right.$ ). The second assumption is that no forecasts are made regarding changes in the unspecified aggregate's multiplier, and thus, $\varepsilon^{*}=\Delta \ln \mathrm{m}^{*}$.

In other words, the Federal Reserve is presumed to be able to predict perfectly the M1 and M2 multipliers, and thus all of the total error in using either of

\footnotetext{
11See Albert E. Burger, "The Relationship Between Monetary Base and Money: How Close?" this Review (October 1975), pp. 5-7.

12Again, this "small" error mest be defined in terms of policymakers preferences as to possible trade-olfs between mean and variance.
}

these variables is due only to projection errors $\left(\gamma_{1}=\mu_{1}\right.$ and $\left.\gamma_{2}=\mu_{2}\right)$. Also the Federal Reserve is presumed to have no knowledge about the future pattern of $m^{*}$ (that is, $\gamma^{*}=c_{1} \Delta \ln m^{*}+\mu^{*}$ ). This latter assumption is equivalent to a situation where the Federal Reserve acts to control the monetary base only, with no regard for probable effects on the monetary aggregates. With these assumptions, equations (5 $\mathrm{a}-\mathrm{b}-\mathrm{c})$ can be rewritten as:

$$
\begin{aligned}
& \text { (6a) } \Delta \ln \mathrm{Y}=\mathrm{a}_{0}+\mathrm{a}_{1} \Delta \ln \mathrm{M} 1+\mu_{1} \\
& \text { (6b) } \Delta \ln \mathrm{Y}=\mathrm{b}_{0}+\mathrm{b}_{1} \Delta \ln \mathrm{M} 2+\mu_{2} \\
& \text { (6c) } \Delta \ln \mathrm{Y}=\mathrm{c}_{0}+\mathrm{c}_{1} \Delta \ln \mathrm{B}+\left(\mathrm{c}_{1} \Delta \ln \mathrm{m}^{*}+\mu^{*}\right)
\end{aligned}
$$

With these assumptions, the test consists of comparing the means and variances of errors made in simulating the percent change of nominal GNP using each of these equations. If the mean of $\gamma^{*}$ is found to be smaller than the mean of both $\mu_{1}$ and $\mu_{2}$, the monetary base is unambiguously superior to either M1 or M2 as a monetary policy tool, in terms of achieving, on average, the desired percent change of nominal GNP over a period of a year. Relative variances of the errors give an indication of how much confidence the Federal Reserve can have in hitting each target. Knowing that the mean error is zero, for example, is not very comforting if the error is +50 percentage points in one year and -50 percentage points in the next.

The results would be ambiguous if the tests revealed that the average total error from using the base $\left(\gamma^{*}\right)$ exceeded either of the errors found for the other monetary aggregates $\left(\mu_{1}\right.$ or $\left.\mu_{2}\right)$. There would also be a problem if the results using the monetary base showed a significantly larger variance relative to the M1 or M2 results. Such findings would then require investigation of the assumptions about the errors in predicting the M1 or M2 multipliers. For example, if the average value of $\gamma$, were found to be 1.0 percent and the mean of $\mu_{1}$ were estimated to be 0.5 percent, with equal variances, the case for the monetary base would require that the average error in predicting the Ml multiplier be at least greater than 0.5 percent or exhibit extreme variance. ${ }^{13}$

13Another issue is the covariance of the control errors and prediction errors generated by the use of $M I$ and $M 2$. The variance of the total errors are

$\operatorname{var}\left(\gamma_{1}\right)=\operatorname{var}\left(a_{1} \varepsilon_{1}\right)+\operatorname{var}\left(\mu_{1}\right)+2 \operatorname{cov}\left(a_{1} \varepsilon_{1} \mu_{1}\right)$

$\operatorname{var}\left(\gamma_{2}\right)=\operatorname{var}\left(b_{1} \varepsilon_{2}\right)+\operatorname{var}\left(\mu_{2}\right)+2 \operatorname{cov}\left(b_{1} \varepsilon_{2} \mu_{2}\right)$

$\operatorname{var}\left(\gamma^{*}\right)=\operatorname{var}\left(c_{1} \Delta \operatorname{lnm} m^{*}\right)+\operatorname{var}\left(\mu^{*}\right)+2 \operatorname{cov}\left(c_{1} \Delta \operatorname{lnm} \mu^{*}\right)$

Thus, even though the variance of $y^{*}$ is approximately equal to the variance of both $\mu_{1}$ and $\mu_{2}$, the variance of the 
If the means and variances of the errors are not significantly different from each other, then another criterion is relevant. That criterion is to select the monetary aggregate which would be the simplest to use in the implementation of monetary policy. The monetary base best meets this criterion, since its use requires less information. The multipliers do not have to be projected.

In light of the preceding discussion, the criterion adopted here is $\mu_{1} \geq \gamma^{*} \leq \mu_{2}$, in terms of both their means and variances. ${ }^{14}$ Given the difference in the sources of the measurable errors, the criterion "stacks the deck" against the monetary base. There is only one measurable type of error present for both M1 and M2 $\left(\mu_{1}\right.$ and $\left.\mu_{2}\right)$, while the measurable error for the base includes two types $\left(c_{1} \Delta \ln \mathrm{m}^{*}+\mu^{*}\right)$. If $\mu_{1}>\gamma^{*}<\mu_{2}$, using the monetary base directly in the implementation of monetary policy would produce more certain achievement of a desired change in nominal GNP than would using either $\mathrm{Ml}$ and $\mathrm{M} 2$ as intermediate targets. If $\gamma^{*}=\mu_{1}=\mu_{2}$, then using the monetary base has the same errors as using $\mathrm{Ml}$ and M2. Consequently, since using the monetary base requires less information than $\mathrm{M} 1$ and $\mathrm{M} 2$, it would be the preferred aggregate for the implementation of monetary policy.

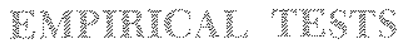

Empirical tests are conducted to determine whether or not $\mu_{1} \geq \gamma^{*} \leq \mu_{2}$, in terms of their means and variances. Since the FOMC presently considers setting monetary policy over four quarters from a recent base period, the relevant error is that associated with such a time interval. First, appropriate empirical forms of equations $(6 \mathrm{a}-\mathrm{b}-\mathrm{c})$ are estimated. Then, errors in post-sample simulations over four quarters of the average percent changes in nominal GNP are estimated for each empirical relationship.

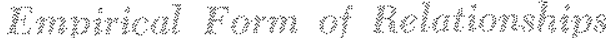

The parameters of equations $(6 \mathrm{a}-\mathrm{b}-\mathrm{c})$ are first estimated by ordinary least squares, using quarterly

total errors in the M1 and M2 cases might be less than the variance of $\gamma^{*}$. Thus, even though the average errors might be equal, the precision of projections using M1 or M2 might be better than that from using the base. This is true if

(1) either $\operatorname{cov}\left(a-\varepsilon_{1} \mu_{1}\right)$ or cov $\left(b_{1} \varepsilon_{2} \mu_{2}\right)$ is negative and, if so,

(2) that covariance is greater than (in absolute terms) one-half of the variance of the control error appropriate for that variable.

1.4If the criterion is met, the problem of making a trade-off decision between means and variances does not arise. data for the period $1 / 1952$ to $I V / 1975$ in order to determine the "best" specification for each equation. A stepwise procedure is used to determine the lag specification of each equation to be used in conducting the test. Regressions are first run using only the contemporaneous observation of each independent variable and two dummy variables, one for the quarter of a major strike and one for the following quarter. Then, the number of lags is increased by one until the final regressions include 10 lagged quarters. The number of lags is selected on the basis of $F$ tests for the significance of each added lag. These tests lead to the acceptance of 5 lagged quarters for changes in $\mathrm{M} 1$ and $\mathrm{B}$ and 3 lagged quarters for changes in $\mathrm{M} 2{ }^{15}$ Also, the constant is not statistically significant from zero in the M2 equation, so its parameters are estimated suppressing the constant.

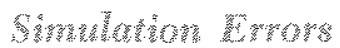

The beyond-sample-period percentage point errors of the simulated percent change in nominal GNP are measured by making simulations over four subsequent quarters. For each aggregate, the equation is first estimated for the sample period $1 / 1952$ to IV/1961 and then reestimated for successive 4 quarter extensions of the sample period (using the specification found to be appropriate for the period $I / 1952-I V / 1975$ ). Using known values of the independent variables, simulations are made of the average quarter-to-quarter percent change in nominal GNP (annual rate) over the four quarters beyond each sample period. The accompanying table presents percentage point errors of the simulations for each post-sample period. The means of the errors and their variances (in both arithmetic and absolute values) are presented at the bottom of the table.

The mean errors are not significantly different from zero (at the 5 percent level) in all three cases, and the variance of the errors using changes in the monetary base is not significantly different from those using changes in either M1 or M2. ${ }^{16}$ These results show that the error in using the monetary base directly as the monetary target in the implementation of mone-

\footnotetext{
15F-texts were run to determine whether there was aty structural change in the equations after the $11 / 1971$ period. No evidence of structural change was found, thus, it is presumed that the lag specification, selected on the basis of the 1/1952-1V/1975 regressions, can be used in estimating the equations for shorter periods in that interyal.

16See Bernard Ostle, Statistics in Research (Annes: The State University of Lowa Press), pp. 119 and 123 for the tests used. The tests indicate that the three distributions of errors are identical.
} 
Toble!

Beyond Sample Period Errors in

Prolecting Average Rate of Change in Nominal GNP

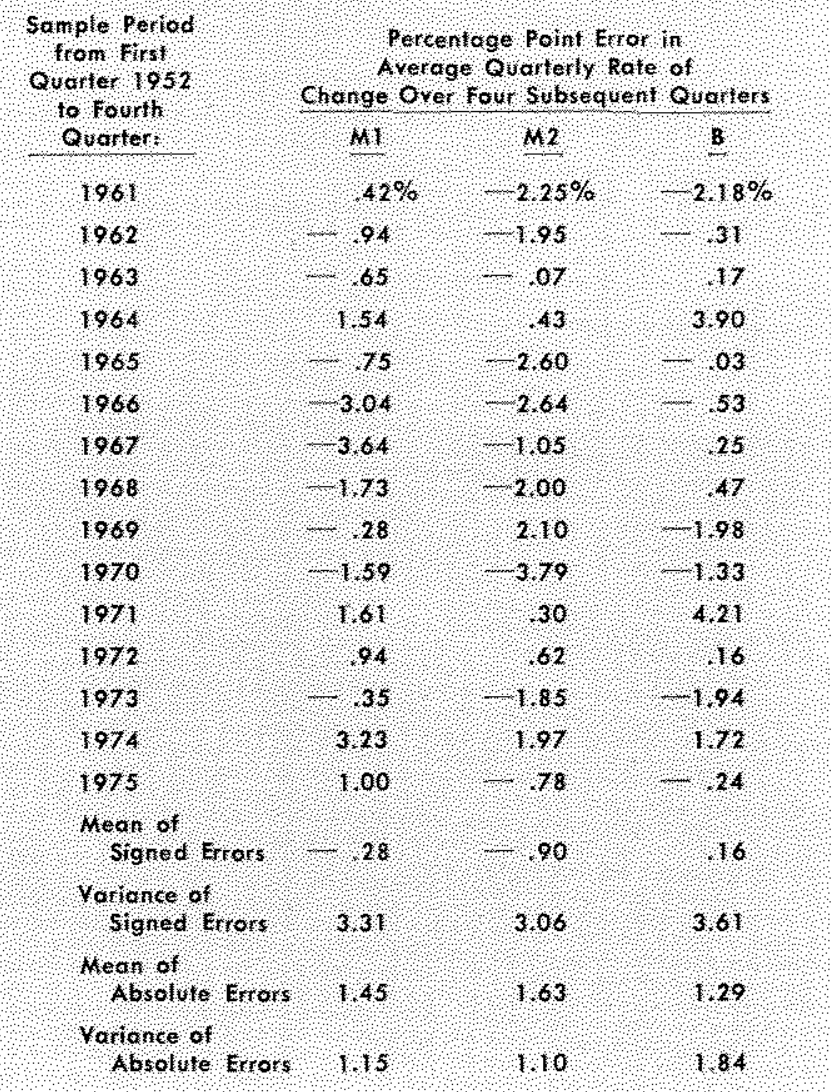

tary policy is at least as small as those resulting from use of $\mathrm{Ml}$ or $\mathrm{M} 2$, over a one year period, even if the Federal Reserve has perfect knowledge of the future patterns of the public's monetary preferences. To the extent that exrors are likely in predicting movements in the multipliers, the case for the monetary base becomes stronger. ${ }^{17}$

17Burger, for example, has found variances for errors in predicting the rate of change of the M1 multiplier of .0576

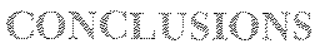

The purpose of this exercise is to cast some light on the relevant considerations in the problem of choosing the appropriate aggregate for monetary policy purposes. The main considerations are projection and control errors in achieving a desired pattern of economic activity. Both types of error must be taken into consideration in determining the appropriate monetary aggregate for the implementation of monetary policy.

The empirical results presented here suggest that, even if the M1 and M2 multipliers could be forecast with virtually no error, the total errors in achieving a desired pattern of economic activity as measured by change in nominal GNP, in terms of their means and variances, probably would not be less than those found for the monetary base. Also, using the monetary base directly in the implementation of monetary policy would be simpler, requiring no estimates of the M1 or M2 multipliers. Consequently, serious consideration should be given to using the monetary base directly as the monetary target in the implementation of monetary policy in place of such intermediate targets as M1 and M2.

for annual periods over the interval IV/1953-IV/1973. See Burger, "The Relationship Between Monetary Base and Money," p. 6 .

Given that the simulation period is four quarters ahead, the variance in the total error for each aggregate would be influenced by the four quarterly variances in the projection errors and the control errors and the namerous covariance terms. As noted in footnote 2 an earlier study found evidence that projection errors did not significantly influence the relative rankings of the measured variances in the errors which are used in the test. Also, the relative sizes of the measured variances in projection errors are inftuenced by the correlation between the included monetary aggregate and exchaded variables which have an inportant influence on nominal GNP. One inportant excluded variable is Government expenditures. A test of the correlation between current and lagged percent changes in each aggregate and high-employment Government expenditures could not reject the null hypothesis that the correlations are equal. 